\title{
Intelligent based technique for under voltage load shedding in power transmission systems
}

\author{
Saiful Firdaus Abd Shukor ${ }^{1}$, Ismail Musirin ${ }^{2}$, Zulkifli Abd Hamid ${ }^{3}$, \\ Mohamad Khairuzzaman Mohamad Zamani ${ }^{4}$, Mohamed Zellagui ${ }^{5}$, Hadi Suyono ${ }^{6}$ \\ ${ }^{1}$ Faculty of Electrical Engineering, Universiti Teknologi MARA (UiTM), Malaysia \\ ${ }^{2,3,4}$ Faculty of Electrical Engineering, Universiti Teknologi MARA (UiTM), Malaysia \\ ${ }^{5}$ Département de Génie Électrique, Faculté de Génie, École de Technologie Supérieure, \\ Université du Québec, Canada \\ ${ }^{6}$ Department of Electrical Engineering, Universitas Brawijaya (UB), Indonesia
}

\begin{tabular}{l} 
Article Info \\
\hline Article history: \\
Received Apr 15, 2019 \\
Revised Jul 16, 2019 \\
Accepted Jul 30, 2019 \\
\hline
\end{tabular}

\section{Keywords:}

Evolutionary programming (EP)

Fifth keyword

Fourth keyword

Objective function (OF)

Under voltage load shedding

(UVLS)

\begin{abstract}
The increasing demand of electric power energy and the presence of disturbances can be identified as the factors of voltage instability condition in a power system. A secure and reliable power system should be considered to ensure smooth delivery of electricity to the consumers. A power system may experience undesired event such as voltage instability condition leading to voltage collapse or cascading collapse if the system experiences lack of reactive power support. Thus, to avoid blackout and cascaded tripping, load shedding is the last resort to prevent a total damage. Under Voltage Load Shedding (UVLS) scheme is one of the possible methods which can be conducted by the power system operators to avoid the occurrence of voltage instability condition. This paper presents the intelligent based technique for under voltage load shedding in power transmission systems. In this study, a computational based technique is developed in solving problem related to UVLS. The integration between a known computational intelligence-based technique termed as Evolutionary Programming (EP) with the under-voltage load shedding algorithm has been able to maintain the system operated within the acceptable voltage limit. Loss and minimum voltage control as the objective function implemented on the IEEE 30-Bus Reliability Test System (RTS) managed to optimally identify the optimal location and sizing for the load shedding scheme. Results from the studies, clearly indicate the feasibility of EP for load shedding scheme in loss and minimum voltage control in power system.
\end{abstract}

Copyright @ 2020 Institute of Advanced Engineering and Science. All rights reserved.

\section{Corresponding Author:}

Saiful Firdaus Abd Shukor, Faculty of Electrical Engineering, Universiti Teknologi MARA Johor, Kampus Pasir Gudang, Malaysia. Email: Saiful541@uitm.edu.my

\section{INTRODUCTION}

Today's electric power systems are often subject to stress due to heavy loading conditions. In addition, the voltage instability is generally created due to component outage or sudden load increments. The current power system network has become more complex and heavily loaded due to growth in electricity demand, achieving maximum economic benefits and maximum transmission capacity efficiency. From literature it is observed that major power blackouts that have occurred around the world were caused by voltage instability. The increasing stress on the traditional power systems has resulted in increased blackouts [1]. One of the main causes of power blackouts is voltage instability which is attributed to 
insufficient generation as well as transmission capacities. In situations where the transmission capacity is not enough for the system to operate normally, power systems employ load shedding mechanisms to reduce the load on the transmission network. Other major challenges faced by power system operators include a change in the nature of loads, the performance of the on-load tap changer transformer, the dependency on generation positioned remotely away from load centers, natural load growth, and the influence of protection and control systems. In these situations, the system may start moving toward collapse. However, before the voltage collapse point, the system enters into a contingency state. A system is said to be in a contingency state if the load on the system exceeds to a certain limit or a sudden change in the load value occurs leading to an outage of a transmission line or a generator [2].

The stability of a system is dependent on the voltage profile of the power network [3, 4]. When a system starts moving toward collapse, one of the indicators is the decline in bus voltages, as the voltage magnitude depends on the reactive power circulating in the system. Therefore, usually when the voltage magnitudes on various buses start to decline, motors are used to recover the voltage magnitude by increasing the amount of reactive power. However, in case of contingency conditions, the existing reactive power sources are not sufficient to stabilize the voltage profile. Moreover, factors such as unexpected load increments or component outages can worsen the situation further. Similarly, voltage instability may not only influence the local load area but may also spread to the adjacent areas in an interconnected power system, commonly known as cascading failures. Traditionally under-voltage load shedding (UVLS) [3] has been used to recover systems in contingency states and avoid a voltage collapse or blackout. UVLS has been proven to be a robust tool in stabilizing systems suffering from low voltage magnitudes $[5,6]$. The success of UVLS in stabilizing a system depends on the optimality of the amount, time and location for load shedding. Shedding lesser or more than the required amount of load does not arrest voltage instability and may even lead to a voltage collapse or over frequency problems, respectively. Similarly, shedding load at the wrong place may cause unnecessary interruption, loss of customer trust, and the utility revenue [7]. The time instant at which load shedding needs to be performed is also very crucial as discussed in [8]. Some of the reliable optimization techniques for UVLS in smart grids are genetic algorithm (GA) and particle swarm optimization (PSO) as reported in [9, 23, 24]. To reduce the computational time, fast search technique can be adopted which involves optimization process. Several optimization techniques can be adopted in order to solve this problem such as; simulated annealing, linear programming, Genetic Algorithm (GA) and Evolutionary Programming (EP). GA and EP are two optimization techniques based on natural generation and specified under subdivisions of Evolutionary Computation (EC) in the Artificial Intelligence (AI) hierarchy. Two other methods under the EC that can be possibly adopted are Evolutionary Strategy (ES) and Genetic Programming (GP). The main difference in these techniques is normally in terms of the evolution methods.

The proposed technique uses the bus voltage as objective function to select and shed the optimal load on the weak buses. The voltage stability margin is highly influenced by the weakest buses in an interconnected power system $[11,14,16,18]$. Therefore, the identification of weak buses is necessary for the planning and operation of power systems. A weak bus is defined as a bus whose load-bearing capability is very low and the voltage magnitude is close to collapse identified by a low voltage value of the bus connected to it.

This paper focuses on developing an intelligent algorithm for undervoltage load shedding, integrated with Evolutionary Programming. The proposed technique has been implemented on the IEEE 30-Bus RTS, resulting convincing results.

\section{RESEARCH METHOD}

\subsection{Overview of Load Shedding}

Load shedding was identified as a corrective action against voltage collapse as proposed in [8]. In this work, voltage modal analysis provided a measure of the relative participation of each bus in voltage collapse scenario. The proposed EP technique revealed that load shedding could be initiated at the most critical locations, while the magnitude of the load to be shed could be determined from the reactive power deficiency and the sensitivity of deficiency to MW load provided by the interior point optimal power flow.

\subsection{Problem Formulation}

In this section, UVLS will represent as an optimization problem. Then this optimization problem is used in the algorithm for UVLS scheme as described in Section 2.3. The main objective for UVLS is to maximize the minimum voltage in the whole system while the sizing of reactive power to be shed and location will be determined by EP. The following equations present the equality and inequality constraints equations involved in this study. 


$$
\begin{aligned}
& P_{i}=V_{i} V_{j} \sum_{j=1}^{N} Y_{i j} \cos \left(\partial_{i j}-\partial_{i}-\partial_{j}\right) \\
& Q_{i}=V_{i} V_{j} \sum_{j=1}^{N} Y_{i j} \sin \left(\partial_{i j}-\partial_{i}-\partial_{j}\right) \\
& V_{i}^{\text {min }} \leq V_{i} \leq V_{i}^{\text {max }}, i \in N_{L}
\end{aligned}
$$

As shown in (1) and (2) represent the equality constraints for active and reactive powers. On the other hand, (3) is the inequality constraint to maintain the voltage between the allowable range of minimum and maximum voltages.

\subsection{Proposed Method}

As mentioned in the previous section, EP involved initialization, fitness calculation, statistics, mutation, combination and selection. Detailed explanations on each step are described below. The overall EP process is represented in the form of flow chart as illustrated in Figure 1.



Figure 1. Flowchart of overall EP structure

Step 1: Initialization: Generate an initial random number of variable $\mathrm{x}_{1}, \mathrm{x}_{2}, \ldots \ldots \mathrm{x}_{\mathrm{N}}$. These random numbers are the control variables which represent the locations and sizing of the load to be shed.

Step 2. Fitness 1: Equation to be optimized. In this study, minimum voltage was used as the objective function and determined using the load flow program.

Step 3: Mutation: Mutation was performed on the generated random numbers, $x_{i}$ to produce the offspring/children. 
Step 4: Fitness 2: Calculation of fitness was conducted utilizing the mutated individuals or offsprings. Step 5: Combination: To combine parents and offspring in in cascade form which in turns doubled the number of individuals in the combined population.

Step 6: Selection: To identify the candidates to be transcribed into the next generation.

Step 7: Convergence Test: To determine the stopping criteria of the evolution.

\section{RESULTS AND ANALYSIS}

In this section, an optimization engine and UVLS algorithm were developed in integrated form in MATLAB. The validation processes were conducted on the IEEE 30-Bus RTS as shown in the single-line diagram in Figure 2. In this study, 4 cases were considered as described in the succeeding sections.

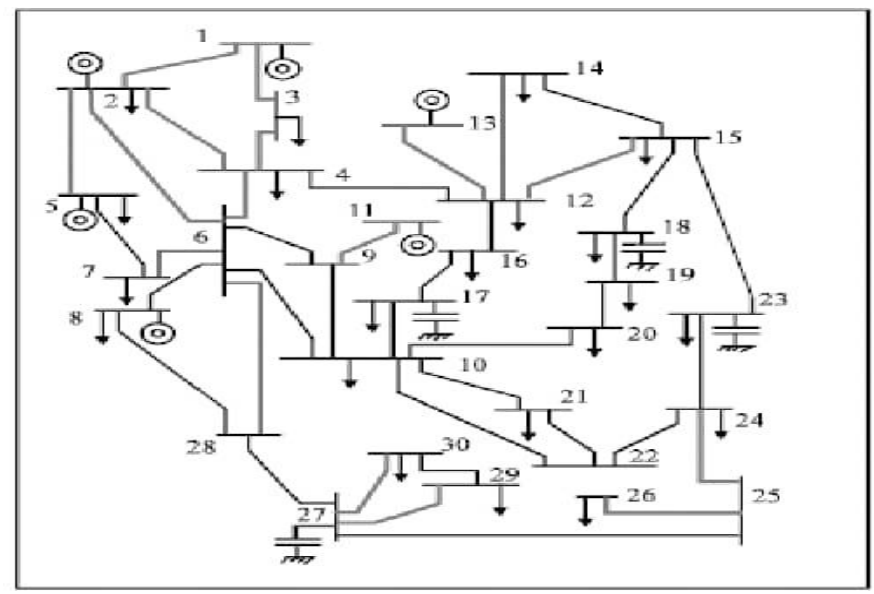

Figure 2. IEEE 30-Bus Reliability Test System (RTS)

\subsection{Case 1: Single Bus Load Shedding}

In this case, six buses have been considered to undergo load variation independently. Buses 14,15 , 16, 18, 21 and 24 are the buses subjected to 30 MVAR load at a time. One load bus was optimally identified by EP to experience the load shedding.

Table 1. Load Shedding Under Single Load

\begin{tabular}{ccccc}
\hline $\begin{array}{c}\text { Tested Bus } \\
\left(Q_{d}=30 \text { MVAR) }\right.\end{array}$ & $\begin{array}{c}\text { Voltage before load } \\
\text { shedding (p.u.) }\end{array}$ & $\begin{array}{c}\text { Voltage after load } \\
\text { shedding (p.u.) }\end{array}$ & $\begin{array}{c}\text { Bus } \\
\text { Location }\end{array}$ & $\begin{array}{c}\text { Amount of load } \\
\text { shed (MVAR) }\end{array}$ \\
\hline 14 & 0.9740 & 0.9901 & 20 & 16.6913 \\
15 & 0.9807 & 1.0035 & 25 & 19.8207 \\
16 & 0.9825 & 1.0016 & 25 & 19.8207 \\
18 & $\mathbf{0 . 9 4 8 7}$ & $\mathbf{0 . 9 8 3 7}$ & $\mathbf{1 9}$ & $\mathbf{1 5 . 3 2 9 9}$ \\
21 & 0.9825 & 1.0037 & 25 & 19.8207 \\
24 & 0.9643 & 1.0006 & 25 & 19.8207 \\
\hline
\end{tabular}

Table 1 tabulates the results of shedding 1 load with the location and amount of reactive power to be shed. Among the 6 buses, bus 18 exhibits the lowest bus voltage 0.9487 p.u. before the implementation of EP-UVLS scheme. This voltage is improved to-0.9837 p.u. with the implementation of UVLS. The proposed EP has identified bus 19 to undergo 15.3299 MVAR reactive load to be shed to improve this voltage value. For $Q_{d 24}=30 \mathrm{MVAR}$, the implementation of integrated EP-UVLS managed to improve the voltage value from 0.9643 p.u. to 1.0006 p.u., which requires an optimal value of 19.8207 MVAR to be shed at bus 25 as the corresponding load bus. Looking at the whole table, it shows that bus 25 is identified as the most frequent load bus to experience load shed regardless of tested bus which was subjected to 30 MVAR load. This information could be useful to power system operators responsible for their UVLS scheme. On the other hand, Figure 3 shows another presentation of results to demonstrate the difference in profile before and after EP-UVLS implementation. Apparently, all the participated buses experience voltage improvement with EPULVS scheme. Figure 3 presents the difference of voltage before the pre and post-load shedding for all the 
participating buses in the system. In general, all the voltage values at all the participating load buses have been increased with the implementation of load shedding scheme.

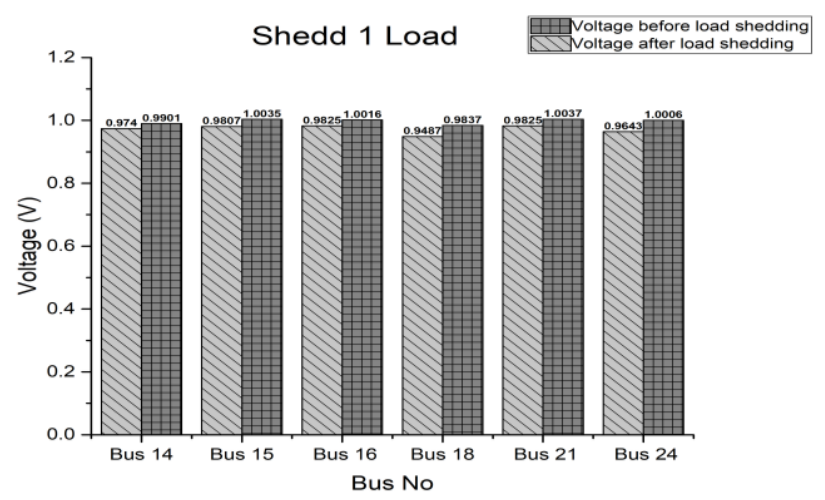

Figure 3. Voltage improvement for single load shedding

\subsection{Case 2: 2 Buses Load Shedding}

In this case, the same 6 load buses i.e. buses 14, 15, 16, 18, 21 and 24 were independently subjected to 30 MVAR. Table 2 tabulates the results for load shedding at 2 buses. In general, all the voltage values have been improved with 2 load buses to be shed. The voltage at bus 18 has been improved within acceptable operating limit even though the voltage is still less than 1.0 p.u..

The proposed EP-UVLS algorithm had indicated that bus 17 and bus 25 as the frequent locations to experience load shedding for all the tested buses. The amount of reactive power to be shed are 12.6528 MVAR and 19.8207 MVAR for buses 17 and 25 respectively as shown in the table. The results for voltage increment at other tested buses can be referred to the same table. Figure 4 presents the difference of voltage before the pre and post-load shedding for all the participating buses in the system. In general, all the voltage values at all the participating load buses have been increased with the implementation of load shedding scheme.

Table 2. Load Shedding Involving 2 Load Buses

\begin{tabular}{ccccccc}
\hline $\begin{array}{c}\text { Tested Bus } \\
(\mathrm{Qd}=30 \mathrm{MVAR})\end{array}$ & $\begin{array}{c}\text { Voltage before } \\
\text { load shedding } \\
\text { (p.u.) }\end{array}$ & $\begin{array}{c}\text { Voltage after load } \\
\text { shedding (p.u.) }\end{array}$ & $\begin{array}{c}\text { Bus } \\
\text { Location 1 }\end{array}$ & $\begin{array}{c}\text { Amount of } \\
\text { load shed } \\
\text { (MVAR) }\end{array}$ & $\begin{array}{c}\text { Bus } \\
\text { Location 2 }\end{array}$ & $\begin{array}{c}\text { Amount of } \\
\text { load shed } \\
\text { (MVAR) }\end{array}$ \\
\hline 14 & 0.974 & 1.0034 & 24 & 17.3649 & 23 & 14.7245 \\
15 & 0.9807 & 1.0043 & 17 & $\mathbf{1 2 . 6 5 2 8}$ & 25 & $\mathbf{1 9 . 8 2 0 7}$ \\
16 & 0.9825 & 1.0042 & 17 & 12.6528 & 25 & 19.8207 \\
18 & 0.9487 & 0.9883 & 19 & 18.8196 & 11 & 15.2303 \\
21 & 0.9825 & 1.0044 & 17 & 12.6528 & 25 & 19.8207 \\
24 & 0.9643 & 1.0041 & 17 & 12.6528 & 25 & 19.8207 \\
\hline
\end{tabular}

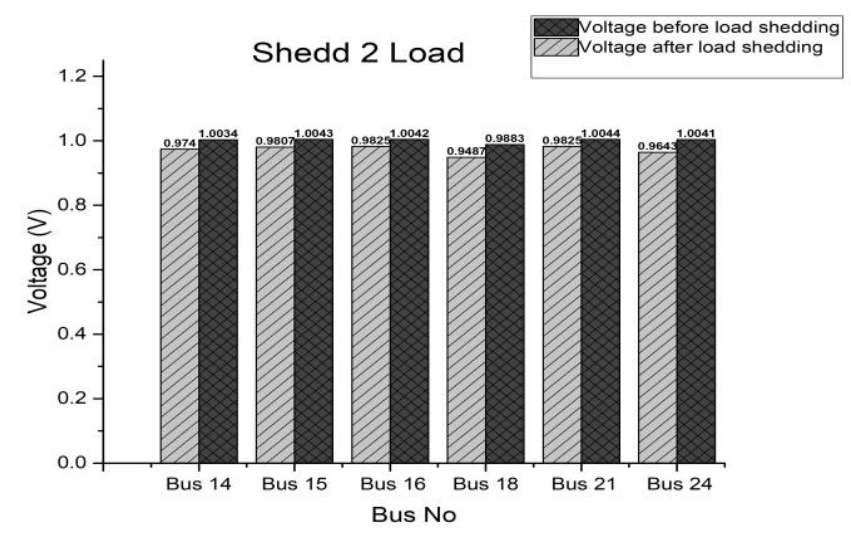

Figure 4. Voltage improvement for load shedding involving 2 load buses 


\subsection{Case 3: 3 Buses Load Shedding}

In this case, the same buses (buses $14,15,16,18,21$ and 24) were tested for load shedding scheme involving 3 load buses. In Table 3, bus 18 which experiences the lowest voltage value has witnessed voltage increment from 0.9487 p.u. to 0.9964 p.u. with load shedding involving 3 load buses. For this load bus, buses 27, 18 and 19 are the optimal location identified by the EP-UVLS scheme; with the corresponding load to be shed worth 5.3863 MVAR, 10.7461 MVAR and 5.74420 MVAR respectively. This is a good indication since the system can still operate within the secure voltage limit even only small reactive loads to be shed at the corresponding buses. Apparently, buses 20, 25 and 28 are the frequent buses recorded as the buses to be shed in this system. One important observation in this case is that, buses 15, 16, 21 and 24 witness identical optimal locations and sizings for load shedding as indicated in Table 3.

Bus 14 almost reaches its maximum value as the table shows the proposed EP gives the same location for the $2^{\text {nd }}$ and the $3^{\text {rd }}$ locations. The variation of voltage value for all the participating load buses for three load shedding scheme is presented in Figure 5.

Table 3. Load Shedding Involving 3 Load Buses

\begin{tabular}{|c|c|c|c|c|c|c|c|c|}
\hline $\begin{array}{c}\text { Tested Bus } \\
(\mathrm{Qd}=30 \mathrm{MVAR})\end{array}$ & $\begin{array}{l}\text { Voltage before } \\
\text { load shedding } \\
\text { (p.u.) }\end{array}$ & $\begin{array}{l}\text { Voltage } \\
\text { after load } \\
\text { shedding } \\
\text { (p.u.) }\end{array}$ & $\begin{array}{c}\text { Bus } \\
\text { Location } \\
1 \\
\end{array}$ & $\begin{array}{c}\text { Amount } \\
\text { of load } \\
\text { shed } \\
\text { (MVAR) }\end{array}$ & $\begin{array}{c}\text { Bus } \\
\text { Location } \\
2 \\
\end{array}$ & $\begin{array}{l}\text { Amount } \\
\text { of load } \\
\text { shed } \\
\text { (MVAR) }\end{array}$ & $\begin{array}{c}\text { Bus } \\
\text { Location } \\
3 \\
\end{array}$ & $\begin{array}{c}\text { Amount } \\
\text { of load } \\
\text { shed } \\
\text { (MVAR) }\end{array}$ \\
\hline 14 & 0.974 & 1.0018 & 23 & 14.7245 & 25 & 19.9892 & 28 & 4.6639 \\
\hline 15 & 0.9807 & 1.0051 & 20 & 19.1072 & 25 & 11.0917 & 28 & 12.4970 \\
\hline 16 & 0.9825 & 1.005 & 20 & 19.1072 & 25 & 11.0917 & 28 & 12.4970 \\
\hline 18 & 0.9487 & 0.9964 & 27 & 5.3863 & 18 & 10.7461 & 19 & 5.74420 \\
\hline 21 & 0.9825 & 1.0052 & 20 & 19.1072 & 25 & 11.0917 & 28 & 12.4970 \\
\hline 24 & 0.9643 & 1.0049 & 20 & 19.1072 & 25 & 11.0917 & 28 & 12.4970 \\
\hline
\end{tabular}

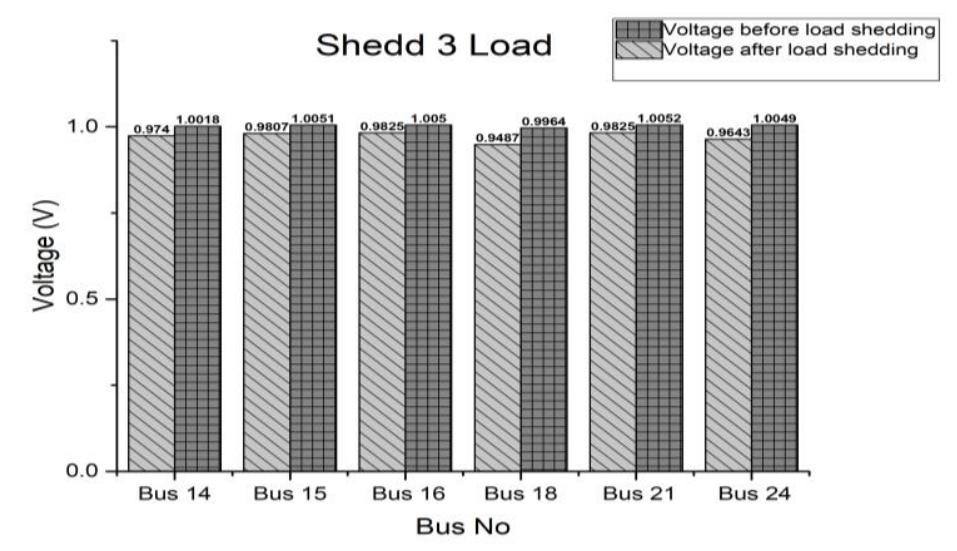

Figure 5. Voltage improvement for load shedding involving 3 load buses

\subsection{Case 4: 4 Buses Load Shedding}

For the last case, 4 buses load shedding scheme involving the similar load buses as the tested buses as those in Case 1, Case 2 and Case 3. The reason of conducting several cases involving similar tested load buses is to see the consistency in terms of voltage increment and sizing of loads. The results for voltage increment, optimal location and sizing are tabulated in Table 4. The lowest voltage experienced by the system when bus 18 was subjected to 30 MVAR has been significantly improved to 0.9994 p.u. when 4 buses are shed. These buses are buses 14, 21, 11 and 20. The corresponding reactive loads to be shed are 3.0744 MVAR, 16.0481 MVAR, 10.689 MVAR and 19.1072 MVAR. Surprisingly bus 21 requires significantly the largest reactive load to be shed worth 16.0481 MVAR as compared other loads. However, the first bus, i.e. bus 14 only requires small reactive load to be shed. In general, it is acceptable since the proposed EP-ULVS is intelligent enough to identify the location and sizing of the reactive load to be shed. Apparently, buses 25 , 13, 24 and 23 are the most frequent buses to experience load shedding. This will become a good indicator for the system when all the 6 buses are involved. 
Table 4. Load Shedding Involving 4 Load Buses

\begin{tabular}{|c|c|c|c|c|c|c|c|c|c|c|}
\hline $\begin{array}{c}\text { Tested Bus } \\
\left(\mathrm{Q}_{\mathrm{d}}=30 \mathrm{MVAR}\right)\end{array}$ & $\begin{array}{c}\text { Voltage } \\
\text { before load } \\
\text { shedding } \\
\text { (p.u.) }\end{array}$ & $\begin{array}{c}\text { Voltage } \\
\text { after load } \\
\text { shedding } \\
\text { (p.u.) }\end{array}$ & $\begin{array}{c}\text { Bus } \\
\text { Loc } 1\end{array}$ & $\begin{array}{l}\text { Amount } \\
\text { of load } \\
\text { shed } \\
\text { (MVAR) }\end{array}$ & $\begin{array}{c}\text { Bus } \\
\text { Loc } 2\end{array}$ & $\begin{array}{l}\text { Amount } \\
\text { of load } \\
\text { shed } \\
\text { (MVAR) }\end{array}$ & $\begin{array}{c}\text { Bus } \\
\text { Loc } 3\end{array}$ & $\begin{array}{c}\text { Amount } \\
\text { of load } \\
\text { shed } \\
\text { (MVAR) }\end{array}$ & $\begin{array}{c}\text { Bus } \\
\text { Loc } 4\end{array}$ & $\begin{array}{c}\text { Amount } \\
\text { of load } \\
\text { shed } \\
\text { (MVAR) }\end{array}$ \\
\hline 14 & 0.974 & 1.0051 & 25 & 16.5563 & 13 & 0.3174 & 24 & 17.3649 & 23 & 14.7245 \\
\hline 15 & 0.9807 & 1.0051 & 25 & 16.5563 & 13 & 0.3174 & 24 & 17.3649 & 23 & 14.7245 \\
\hline 16 & 0.9825 & 1.005 & 25 & 16.5563 & 13 & 0.3174 & 24 & 17.3649 & 23 & 14.7245 \\
\hline 18 & 0.9487 & 0.9994 & 14 & 3.0744 & 21 & 16.0481 & 11 & 10.689 & 20 & 19.1072 \\
\hline 21 & 0.9643 & 1.0052 & 25 & 16.5563 & 13 & 0.3174 & 24 & 17.3649 & 23 & 14.7245 \\
\hline 24 & 0.9643 & 1.0050 & 25 & 16.5563 & 13 & 0.3174 & 24 & 17.3649 & 23 & 14.7245 \\
\hline
\end{tabular}

Further results presentation for this case is depicted in Figure 6. This figure demonsrates that the implementation of load shedding involving 4 buses has managed to improve the voltage profile at all the participating buses in the system. The idea is to show the graphical presentation for voltage increment at all the participating load buses to be tested. In general, all the voltage levels are within the operable voltage limit i.e. $0.95<V_{m}<1.05$ p.u.as stipulated by most standards in power utilities.

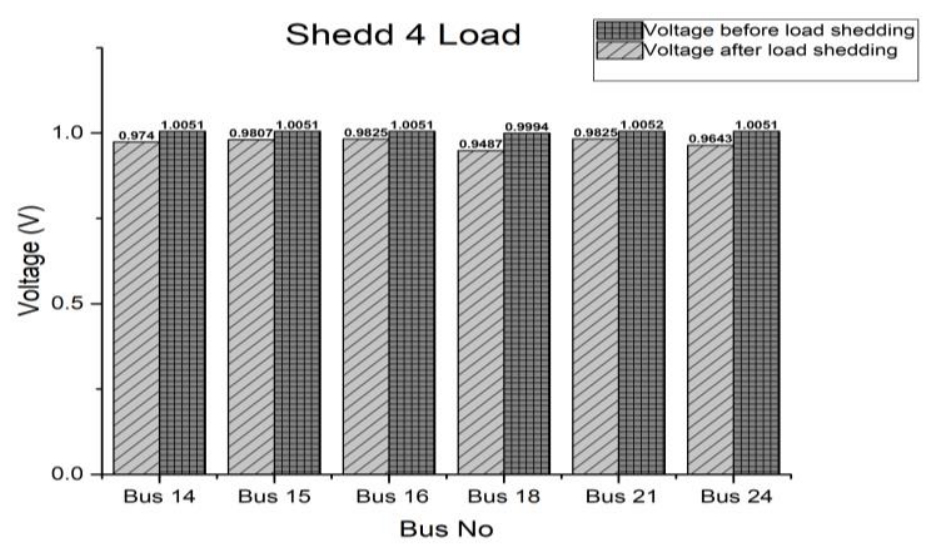

Figure 6. Voltage improvement for load shedding involving 4 load buses

\section{CONCLUSION}

This paper has presented intelligent based technique for under voltage load shedding in power transmission systems. In this study, an integrated intelligent which combined EP and UVLS termed as EPUVLS has been developed and validated on the IEEE 30-Bus Reliability Test System (RTS). The proposed EP-UVLS algorithm has significantly improved the voltage profile of a power system which is feasible to avoid a power blackout. The proposed integrated EP-UVLS technique has shown its capability to find the optimal location and sizes of reactive power (MVAR) with the objective to improve the voltage profile in the transmission system. All of the objectives in this study have been significantly achieved. However, there is still room for improvement. For instance, new technique such as Monte-Carlo can be integrated in the initialization process in order to generate the random number. The proposed EP-UVLS can also be improved in terms of its computational time by integrating fast search technique subject to further study. Furthermore, integration of renewable energy (RE) can also be installed in the system to see the impact of its presence in load shedding scheme. Results from the study can also be taken as early indication and information for the planning in power system.

\section{ACKNOWLEDGEMENTS}

The authors would like to acknowledge The Institute of Research Management and Innovation (IRMI) UiTM, Shah Alam, Selangor, Malaysia and Ministry of Education (MOE) for the support of this research. This research is supported by Ministry of Education (MOE) under the Fundamental Research Grant Scheme (FRGS) with project code: 600-RMI/FRGS 5/3 (0102/2016). 


\section{REFERENCES}

[1] V. Hosseinnezhad, M. Rafiee, M. Ahmadian, and P. Siano, "Optimal island partitioning of smart distribution systems to improve system restoration under emergency conditions," International Journal of Electrical Power \& Energy Systems, vol. 97, pp. 155-164, 2018/04/01/2018.

[2] M. E. Jabian, R. Funaki, and J. Murata, "Load Shedding Optimization Considering Consumer Appliance Prioritization Using Genetic Algorithm for Real-time Application," IFAC-PapersOnLine, vol. 51, pp. 486-491, 2018/01/01/ 2018.

[3] X. Lu, K. Zhou, X. Zhang, and S. Yang, "A systematic review of supply and demand side optimal load scheduling in a smart grid environment," Journal of Cleaner Production, vol. 203, pp. 757-768, 2018/12/01/ 2018.

[4] F. M. Echavarren, E. Lobato, and L. Rouco, "A corrective load shedding scheme to mitigate voltage collapse," International Journal of Electrical Power \& Energy Systems, vol. 28, pp. 58-64, 2006/01/01/ 2006.

[5] S. Arnborg, G. Andersson, D. J. Hill, and I. A. Hiskens, "On undervoltage load shedding in power systems," International Journal of Electrical Power \& Energy Systems, vol. 19, pp. 141-149, 1997/02/01/ 1997.

[6] V. Tamilselvan and T. Jayabarathi, "A hybrid method for optimal load shedding and improving voltage stability," Ain Shams Engineering Journal, vol. 7, pp. 223-232, 2016/03/01/ 2016.

[7] T. N. Le, H. A. Quyen, and N. A. Nguyen, "Application of fuzzy-analytic hierarchy process algorithm and fuzzy load profile for load shedding in power systems," International Journal of Electrical Power \& Energy Systems, vol. 77, pp. 178-184, 2016/05/01/ 2016.

[8] T. Amraee, A. M. Ranjbar, B. Mozafari, and N. Sadati, "An enhanced under-voltage load-shedding scheme to provide voltage stability," Electric Power Systems Research, vol. 77, pp. 1038-1046, 2007/06/01/ 2007.

[9] N. I. Voropai, D. N. Efimov, A. B. Osak, D. A. Panasetsky, E. A. Novikov, and B. N. Karatayev, "Distributed Adaptive Load Shedding Scheme to Maintain Transient Stability and Prevent Overload," IFAC-PapersOnLine, vol. 48, pp. 554-559, 2015/01/01/ 2015.

[10] A. Ahmadi and Y. Alinejad-Beromi, "A new integer-value modeling of optimal load shedding to prevent voltage instability," International Journal of Electrical Power \& Energy Systems, vol. 65, pp. 210-219, 2015/02/01/ 2015.

[11] W. Liu, W. Gu, Y. Xu, S. Xue, M. Chen, B. Zhao, et al., "Improved average consensus algorithm based distributed cost optimization for loading shedding of autonomous microgrids," International Journal of Electrical Power \& Energy Systems, vol. 73, pp. 89-96, 2015/12/01/ 2015.

[12] Z. A. Hamid and I. Musirin, "Optimal Fuzzy Inference System incorporated with stability index tracing: An application for effective load shedding," Expert Systems with Applications, vol. 41, pp. 1095-1103, 2014/03/01/ 2014.

[13] M. T. Devine and V. Bertsch, "Examining the benefits of load shedding strategies using a rolling-horizon stochastic mixed complementarity equilibrium model," European Journal of Operational Research, vol. 267, pp. 643-658, 2018/06/01/2018

[14] L. D. Arya, P. Singh, and L. S. Titare, "Differential evolution applied for anticipatory load shedding with voltage stability considerations," International Journal of Electrical Power \& Energy Systems, vol. 42, pp. 644-652, 2012/11/01/2012.

[15] N. N. A. Bakar, M. Y. Hassan, M. F. Sulaima, M. N. i. Mohd Nasir, and A. Khamis, "Microgrid and load shedding scheme during islanded mode: A review," Renewable and Sustainable Energy Reviews, vol. 71, pp. 161-169, 2017/05/01/ 2017.

[16] J. Deng and J. Liu, "A Study on a Centralized Under-Voltage Load Shedding Scheme Considering the Load Characteristics," Physics Procedia, vol. 24, pp. 481-489, 2012/01/01/ 2012.

[17] M. M. Hosseini-Bioki, M. Rashidinejad, and A. Abdollahi, "An implementation of particle swarm optimization to evaluate optimal under-voltage load shedding in competitive electricity markets," Journal of Power Sources, vol. 242, pp. 122-131, 2013/11/15/ 2013.

[18] R. Kanimozhi, K. Selvi, and K. M. Balaji, "Multi-objective approach for load shedding based on voltage stability index consideration," Alexandria Engineering Journal, vol. 53, pp. 817-825, 2014/12/01/ 2014.

[19] A. Khamis, H. Shareef, A. Mohamed, and Z. Y. Dong, "A load shedding scheme for DG integrated islanded power system utilizing backtracking search algorithm," Ain Shams Engineering Journal, vol. 9, pp. 161-172, 2018/03/01/ 2018.

[20] X. Fu and X. Wang, "Determination of load shedding to provide voltage stability," International Journal of Electrical Power \& Energy Systems, vol. 33, pp. 515-521, 2011/03/01/ 2011.

[21] N. Sadati, T. Amraee, and A. M. Ranjbar, "A global Particle Swarm-Based-Simulated Annealing Optimization technique for under-voltage load shedding problem," Applied Soft Computing, vol. 9, pp. 652-657, 2009/03/01/ 2009.

[22] J. A. Laghari, H. Mokhlis, A. H. A. Bakar, and H. Mohamad, "Application of computational intelligence techniques for load shedding in power systems: A review," Energy Conversion and Management, vol. 75, pp. 130-140, 2013/11/01/ 2013 .

[23] N. Z. Mohd Ali, I. Musirin, H. Mohamad, Clonal "Evolutionary Particle Swarm Optimization for Congestion Management and Compensation Scheme in Power system," Indonesian Journal of Electrical Energy and Computer Science" vol. 16 No 2. November 2019

[24] Gitanjali Saha, Kabir Chakraborty, Priyanath Das "Voltage Stability Prediction on Power Networks using Artificial Neural Networks" Indonesian Journal of Electrical Energy and Computer Science" vol. 10 No 1. April 2018

[25] J. Sasikala and M. Ramaswamy, "Fuzzy based load shedding strategies for avoiding voltage collapse," Applied Soft Computing, vol. 11, pp. 3179-3185, 2011/04/01/ 2011. 